\title{
Adolescent exposure to drink driving as a predictor of young adults' drink driving
}

\author{
Tracy J. Evans-Whipp ${ }^{\mathrm{a}, \mathrm{b}, *, 1}$, Stephanie M. Plenty ${ }^{\mathrm{a}, 1}$, John W. Toumbourou ${ }^{\mathrm{a}, \mathrm{c}}$, Craig Olsson $^{\mathrm{a}, \mathrm{c}}$, \\ Bosco Rowland ${ }^{\mathrm{c}}$, Sheryl A. Hemphill ${ }^{\mathrm{d}}$ \\ a Centre for Adolescent Health, Royal Children's Hospital \& Adolescent Health Research, Murdoch Children's Research Institute, Parkville, Victoria 3052, Australia \\ b The University of Melbourne Department of Paediatrics, Royal Children's Hospital, Parkville, Victoria 3052, Australia \\ c Prevention Sciences, School of Psychology and Centre for Mental Health and Wellbeing Research, Deakin University, Waterfront Campus, Geelong, Victoria 3217, Australia \\ d School of Psychology, Australian Catholic University, Fitzroy, Victoria 3065, Australia
}

\section{A R T I C L E I N F O}

Article history:

Received 30 July 2012

Received in revised form 12 October 2012

Accepted 13 November 2012

\section{Keywords:}

Drink driving

Driving under the influence

Adolescence

Alcohol

Riding with drinking driver

\begin{abstract}
A B S T R A C T
The purpose of this study was to investigate the influence of exposure to others' drink driving during adolescence on self-reported driving under the influence (DUI) of alcohol in young adulthood. Data were drawn from 1956 participants with a driving license enrolled in the International Youth Development Study from Victoria, Australia. During 2003 and 2004, adolescents in Grades 7, 9 and 10 (aged 12-17) completed questionnaires examining whether they had ridden in a vehicle with a driver who had been drinking, as well as other demographic, individual, peer and family risk factors for DUI. In 2010, the same participants (aged 18-24) then reported on their own DUI behaviour. 18\% of young adults with a driving license reported DUI in the past 12 months. Exposure to others' drink driving during adolescence was associated with an increased likelihood of DUI as a young adult ( $O R=2.13,95 \%$ CI $1.68-2.69)$. This association remained after accounting for the effects of other potential confounding factors from the individual, peer and family domains $(\mathrm{OR}=1.62,95 \% \mathrm{CI} 1.23-2.13)$. Observing the drink driving behaviours of others during adolescence may increase the likelihood of DUI as a young adult. Strategies to reduce youth exposure to drink driving are warranted.
\end{abstract}

(c) 2012 Elsevier Ltd. All rights reserved.

\section{Introduction}

Traffic accidents and drink driving are serious health concerns for the young adult population. Road fatality is the leading cause of death among young adults in Australia and the US (Australian Institute of Health and Welfare, 2008; Australian Medical Association, 2009; Australian Transport Council, 2008; Hoyert et al., 2005). For example, traffic accidents account for 31\% of all deaths in young Australians aged 15-24 years (Australian Bureau of Statistics, 2008). This is higher than the road fatality rate in any other age group (Australian Institute of Health and Welfare, 2008; Transport Accident Commission of Victoria, 2003). Alcohol plays a key role in many fatal accidents (Siskind et al., 2011), with up to $50 \%$ of U.S. road fatalities amongst 18-24 year olds involving alcohol (Hingson et al., 2009; National Highway Traffic Safety Administration, 2004). Approximately 25\% of all drivers killed on Australian roads have a blood alcohol concentration (BAC) above

\footnotetext{
* Corresponding author. Tel.: +61 39345 6677; fax: +61 393456343.

E-mail addresses: tracy.evanswhipp@mcri.edu.au (T.J. Evans-Whipp), stephanie.plenty@mcri.edu.au (S.M. Plenty), craig.olsson@rch.org.au (C. Olsson), bosco.rowland@deakin.edu.au (B. Rowland), sheryl.hemphill@acu.edu.au (S.A. Hemphill).

1 Tracy Evans-Whipp and Stephanie Plenty are joint first authors.
}

the legal limit (0.05\%) (Australian Transport Council, 2008; Office of Road Safety, 2012). Additionally, young drivers are at increased risk of road accidents compared to older drivers with the same BAC (Cavallo and Triggs, 1996; Engström et al., 2003; Palamara et al., 2001).

Young adult drink driving is prevalent, with self-report estimates ranging from 20 to 25\% in Australian and US studies (Beck et al., 2010; Davey et al., 2005; Hingson et al., 2009; LaBrie et al., 2011; Vassallo et al., 2010). Given this high prevalence and that young adults are over-represented in road accidents there is an important need to identify approaches that can help reduce driving under the influence (DUI) of alcohol in this population.

Previous research has identified a number of key risk factors associated with DUI. These factors span the demographic, family, peer, personality and community domains. A key risk factor for DUI is frequent and intense (binge) alcohol use (Bingham et al., 2007; LaBrie et al., 2010; Tin Tin et al., 2008; Vassallo et al., 2010). Earlier alcohol initiation has also been shown to increase the likelihood of DUI (Hingson et al., 2009; Tomas Dols et al., 2010). Demographic risk factors include being male (Beck et al., 2010; Bina et al., 2006; LaBrie et al., 2011; Vassallo et al., 2007) and lower socio-economic status (Morrison et al., 2002; Vaez and Laflamme, 2005). Other individual characteristics associated with DUI include greater levels of aggression (Bingham et al., 2007), delinquency (Bingham et al., 2007), impulsivity (Pedersen and McCarthy, 2008) and sensation 
seeking (Fernandes et al., 2007; Jonah et al., 2001; Pedersen and McCarthy, 2008; Zakletskaia et al., 2009). The family context is also relevant as poor family relationships (Tomas Dols et al., 2010) and parent alcohol use (LaBrie et al., 2010; Maldonado-Molina et al., 2011) have been shown to predict DUI. Family factors can also play a protective role. For example, adolescent perceptions of supportive relationships with their parents and schools may protect against DUI (Tin Tin et al., 2008). Within the broader community context, perceiving that others in the community hold permissive attitudes towards DUI has been shown to be associated with a greater tendency to drink drive (Bingham et al., 2007; Chen et al., 2008).

The attitudes others hold towards drink driving can be expected to exert a particularly strong influence during adolescence as attitudes and expectations of acceptable behaviour are developing. Children and adolescents rely on lifts from others and many high school students accept rides from drivers who have been drinking alcohol (Centers for Disease Control and Prevention, 2010). In this sense, the importance of other drivers as role models in the socialization process should not be underestimated. Social learning theory proposes that normative values and behaviours are learnt by observing others' actions (Bandura, 1977, 1986). There is a body of evidence that supports the social modelling effect in many areas of development, such as the relationship between parent alcohol use and a child's alcohol use (Ward et al., 2010), as well as the accident driving records shared between parents and their children (Ferguson et al., 2001). The current study proposes that exposure during adolescence to others' drink driving is an important potentially modifiable risk factor worthy of investigation.

Some previous studies have explored the link between exposure to others' drink driving and DUI. Cross-sectional data from the U.S. National Survey on Drug Use and Health indicated that 16 and 17 year olds were more likely to drink drive if they lived with a mother or father who also had driven under the influence in the past year (Center for Behavioral Health Statistics and Quality, 2011). In a cross-sectional study of Canadian high school students, Leadbeater et al. (2008) found that having ridden with a drink driving peer predicted students' DUI. This effect was stronger if they had more frequent exposure to adults' drink driving. In a longitudinal New Zealand study, Gulliver and Begg (2004) investigated the influence of riding with an alcohol impaired driver during adolescence on DUI at age 21. A path analysis showed that, for males, exposure to adult DUI at age 15 predicted travelling with an alcohol impaired peer at age 18 , which in turn increased the chance of DUI at age 21 . These studies highlight the possible influence of observing drink driving during adolescence. However, they have some limitations in terms of study design and consideration of potential confounders. The first two are cross-sectional and the third utilized a relatively small sample of only male young adults. Furthermore, none of the studies accounted for a range of important confounding factors. Therefore it is uncertain if the relationship between riding with a drinking driver and DUI would remain above and beyond the influence of other risk factors (such as sensation seeking). Furthermore, some other previous studies have combined measures of exposure to DUI with an individual's own DUI (e.g. Finken et al., 1998; McCarthy and Pedersen, 2009), making it impossible to disentangle the effects of exposure compared to a young adult's prior behaviour. No single study has used a longitudinal design with a large sample of young adults whilst accounting for a range of risk factors for drink driving.

The purpose of this study is to investigate the influence of adolescent exposure to others' drink driving on later self-reported DUI in young adulthood. The study is based on a representative sample of Victorian Australian school students followed from adolescence to young adulthood. It is hypothesised that adolescent exposure to others' drink driving will increase the likelihood of DUI as a young adult. It is also expected that this effect will remain after accounting for the influence of other important confounding factors in the demographic, family, peer and individual domains.

\section{Materials and methods}

\subsection{Participants and procedure}

Data for this paper come from a larger study, the International Youth Development Study (IYDS). The IYDS is a multi-cohort longitudinal study that investigates the etiology of substance use and associated problems for adolescents from Victoria, Australia and Washington State, U.S. In 2002 the IYDS used a two-stage cluster sampling approach to recruit statewide representative samples of students from three age cohorts, Grades 5, 7 and 9. Participants came from 152 schools in Victoria and 153 schools in Washington State. Across the three cohorts 2885 (74.8\%) of eligible Washington State parents and students consented to participate and 2884 (73.5\%) of eligible Victorian parents and students consented to participate (see McMorris et al., 2007 for more details regarding recruitment).

Data from the current study are drawn from Victorian participants. At time 1, a total of 2821 participants in three cohorts were surveyed when they were in Grades 7, 9 or 10 . The Grade 10 cohort $(n=907)$ was surveyed in 2003 and the Grades 7 and 9 cohorts ( $n=955$ and $n=959$ respectively) were surveyed in 2004. At time 1 participants were aged $12-17$ (median age $=15.0$; interquartile range 13.3-15.7). At time 2 (2010), 2397 (85\% retention rate) participants completed surveys again as young adults when they were 18-24 years of age (median age 21.0; interquartile range 19.3-22.6). Of these, $83 \%$ reported that they had a vehicle license. The current study includes a total of 1956 young adults with a vehicle license who had complete data available for both time-points.

Ethics approval was first gained through the Ethics in Human Research Office at the Royal Children's Hospital in Victoria. At time 1 permission was then gained from the Department of Education and Training for government schools and the Catholic Education Office for some private schools and then by school principals. Parents provided written consent for their child to participate in the study and students provided assent to complete the survey. Students completed surveys during a 50-60 min class period. Students absent on the day of testing completed the survey under the supervision of trained school personnel, or in a small percentage of cases (approximately 4\%), over the telephone with study staff. At time 2 , as young adults, participants provided consent for their own participation. They either completed a questionnaire online (77.5\%), over the telephone with trained study staff $(1.5 \%)$, or returned a postal survey (less than $5 \%$ ).

\subsection{Measures}

\subsubsection{Outcome variable}

Young adult drink driving (DUI). At time 2, as young adults, participants were asked how often they had driven when probably affected by alcohol since gaining their license (adapted from the Australian Temperament Project, see Prior et al., 2000; Vassallo et al., 2002). Response options ranged from never to whenever I can on a 7-point scale. Responses were recoded to generate a dichotomous variable with responses of never versus at least once. Less than $2 \%$ of respondents selected more frequently than the second response option of occasionally.

\subsubsection{Exposure variable}

Riding with a drinking driver during adolescence. At time 1, students were asked how many times during the past year they had ridden in a car or other motor vehicle driven by someone who had been drinking alcohol (adapted from the Youth Risk 
Behavior Survey (YRBS) High School Questionnaire (Brener et al., 2002; Centers for Disease Control and Prevention, 2010)). Response options ranged from Never, 1 or 2 times, to 40 or more times on an eight-point scale. Responses were skewed with relatively few respondents selecting 3 or more times (13\%). Responses were recoded to generate a dichotomous variable with responses reflecting never during the past year versus at least once during the past year.

\subsubsection{Confounding factors measured during adolescence}

Demographics. Information on students' gender, age and family socio-economic status was also collected. A single composite measure of family socioeconomic status (SES) was calculated from responses to questions on maternal and paternal education status and family income. This information was provided in a separate telephone interview with a parent/guardian of each student in the first year of the study (2002) as described in Evans-Whipp et al. (2007). The SES variable was a continuous measure with a higher score indicating a higher level of SES.

The following factors were measured at time 1 during adolescence.

Poor family management. This scale came from the Communities that Care Youth Survey (Arthur et al., 2002; Glaser et al., 2005). It asked participants if their parents: would know if they did not come home on time, know who they are with when they are not home, ask if they have done their homework, have clear rules in the family, have clear rules about alcohol and drug use, want them to call if they are going to be home late, would find out if they drank alcohol, carried a weapon or skipped school without their permission. Response options were on a four-point scale ranging from definitely no to definitely yes (Cronbach's Alpha = .83).

Family history of antisocial behaviour. This scale also came from the Communities that Care Youth Survey (Arthur et al., 2002; Glaser et al., 2005). It asked participants if any of their siblings had ever smoked cigarettes, drunk alcohol, used marijuana, taken a weapon to school, been suspended from school and if anyone in the family had ever had a severe alcohol or drug problem. Participants indicated yes or no. They were also asked how many adults they had known in the past year who had gotten drunk or high, used marijuana, sold drugs or done other things that could get them in trouble with the police. Response options ranged from none to 5 or more adults on a five-point scale (Cronbach's Alpha $=.76$ ).

Binge alcohol use reflected students who indicated that they had drunk five or more alcoholic drinks in a row at least once during the last two weeks compared to those who had not. This measure was adapted from the Communities that Care Survey (Arthur et al., 2002; Glaser et al., 2005).

Sensation seeking. Participants were asked how many times they have: done crazy things even if they are a little dangerous, done something dangerous because someone dared you to do it and done what feels good no matter what. These items were adapted from the Seattle Social Development Project (SSDP) SensationSeeking/Disinhibition scale (Hawkins et al., 2003). Response options ranged from never to once a week or more on a six-point scale (Cronbach's Alpha $=.80$ ).

Rebelliousness. Participants responded to the following three statements from the Personal Experiences Inventory (Winters and Henly, 1989). I do the opposite of what people tell me, just to get them mad, I ignore rules that get in my way and I like to see how much I can get away with. Response options were on a fourpoint scale ranging from definitely no to definitely yes (Cronbach's Alpha $=.81$ ).

Friends' use of drugs was measured by asking how many of the student's friends in the past year had: smoked cigarettes, tried alcohol, used marijuana or used other illegal drugs. Items were adapted from the SSDP Deviant Peer Involvement and Interaction scale
(Hawkins et al., 2003). Response options ranged from none of my friends to 4 of my friends on a 5 point scale (Cronbach's Alpha =.77).

The mean of responses to items within each subscale formed measures of poor family management, family history of antisocial behaviour, sensation seeking, rebelliousness, and friends' use of drugs.

\subsection{Statistical analysis}

The following analyses are based on the sample of 1956 respondents from 3 grade cohorts described above. To compare the frequencies and means of exposure and potential confounder variables in drink driving and non-drink driving groups, chi square tests for categorical variables and $t$-tests for continuous variables were performed. The unadjusted association between riding with a drinking driver during adolescence and young adult drink driving was then examined in a bivariate logistic regression. A series of logistic regressions was also performed to identify associations between each potential confounder with young adult DUI. A multivariate logistic regression predicting young adult drink driving was then performed to test the predictive value of riding with a drinking driver during adolescence while accounting for the influence of potential confounding risk factors. To identify differential effects between subgroups within the sample, interactions between gender, age and cohort with adolescent exposure to riding with a drinking driver were also tested. However, none were significant and so the results are pooled across all participants.

\section{Results}

\subsection{Descriptive statistics}

As shown in Table 1, 34\% of adolescents reported riding with a drinking driver at least once in the past year. As young adults, $18 \%$ of participants reported DUI in the past year. A statistically significantly higher proportion of young adults who had ridden with a drinking driver during adolescence reported DUI compared to those who reported DUI but had not ridden with a drinking driver in adolescence ( $26 \%$ versus $14 \%, \mathrm{chi}^{2}=41.33, p<.001$ ).

Descriptive statistics for potential confounding factors are also presented in Table 1 . These showed differences on all factors between self-reported young adult drink drivers and non-drink drivers. A greater proportion of young adult drink drivers reported binge drinking during adolescence and were male compared to non-drink drivers. Drink drivers also reported higher rates of other individual and peer level risk factors during adolescence than nondrink drivers. They also showed higher rates of family history of antisocial behaviour, poor family management and higher family SES.

\subsection{Bivariate associations between riding with a drinking driver during adolescence, confounding factors and young adult DUI}

A series of logistic regressions were performed for riding with a drinking driver during adolescence and each potential confounder with young adult DUI (see Table 2). These analyses showed that adolescents exposed to others' drink driving were approximately twice as likely to drive under the influence of alcohol as a young adult. Males were three times more likely to DUI than females. All confounding factors measured also showed statistically significant associations, increasing the likelihood of young adult DUI. No statistically significant interactions between gender, age and cohort with riding with a drinking driver during adolescence were observed. 
Table 1

Means and prevalence of key variables for young people with a driver's license.

\begin{tabular}{|c|c|c|c|}
\hline Adolescent risk factor & Whole sample $(N=1956)$ & Non-drink drivers $(N=1599)$ & Drink drivers $(N=357$ \\
\hline Adolescent exposure to DUI & $34.15 \%$ & $14.21 \%$ & $26.05 \%{ }^{* * *}$ \\
\hline Gender - Male & $45.81 \%$ & $41.03 \%$ & $67.23 \%^{* * *}$ \\
\hline Age & $14.76(1.23)$ & $14.67(1.24)$ & $15.17(1.09)^{* * *}$ \\
\hline Binge drinking & $27.90 \%$ & $25.31 \%$ & $39.55 \%{ }^{* * *}$ \\
\hline Sensation seeking & $2.55(1.32)$ & $2.43(1.27)$ & $3.09(1.41)^{* * *}$ \\
\hline Rebelliousness & $1.99(.67)$ & $1.96(.67)$ & $2.12(.64)^{* * *}$ \\
\hline Family history of ASB & $1.93(.81)$ & $1.88(.80)$ & $2.13(.84)^{* * *}$ \\
\hline Poor family management & $1.80(.53)$ & $1.77(.53)$ & $1.94(.50)^{* * *}$ \\
\hline Family SES & $1.96(.50)$ & $1.95(.50)$ & $2.02(.52)^{*}$ \\
\hline Friends' drug use & $2.08(1.01)$ & $2.01(.99)$ & $2.39(1.03)^{* * *}$ \\
\hline
\end{tabular}

Family history of ASB = family history of antisocial behaviour; standard deviations for continuous variables are in parenthesis.

${ }^{*} p<.05$.

*** $p<.001$.

\subsection{Multivariate associations between riding with a drinking} driver during adolescence, confounding factors and DUI

Next, a multivariate logistic regression was performed to examine the main effects of riding with a drinking driver during adolescence on young adult DUI after the effects of key confounding factors were taken into account. Pairwise correlation analyses indicated weak to moderate correlations amongst the predictor variables ( $r$ ranged from -.12 to .49), indicating no signs of multicollinearity amongst these risk factors. As shown in Table 2, in the multivariate model, riding with a drinking driver during adolescence was associated with young adult DUI, increasing the likelihood by $62 \%$. Other significant risk factors included being male, older in age, sensation seeking and higher family SES. Males were two and a half times more likely to DUI than females.

\section{Discussion}

This large longitudinal study examined the predictive relationship between self-reported DUI in young adulthood and riding with a drinking driver during adolescence in a large community sample in Victoria, Australia. As hypothesised, it found that exposure to drink driving during adolescence is a risk factor in young adulthood. Even when taking into account other key influences on DUI there was a greater than 60 percent increase in the likelihood of DUI for those who reported riding with a drinking driver at least once in the past year in adolescence. Other variables found to be related to DUI were being male, increased age, sensation-seeking and higher SES.

The finding of the link between adolescent exposure to DUI and subsequent young adult DUI adds to the small body of research using longitudinal studies to understand the influence of personal, family and social characteristics on the development of risky driving behaviours (Gulliver and Begg, 2004; Reeder et al., 1998; Vassallo et al., 2007) and extends previous cross-sectional findings (Leadbeater et al., 2008). Consistent with major social learning frameworks of behaviour (Akers, 1985; Bandura, 1977, 1986; Catalano and Hawkins, 1996) it hypothesised this effect largely occurs through the influence of observing adult role models on the development of normative attitudes to DUI in adolescence.

It is apparent that many adolescents are being exposed to others' drink driving. Over one third of the adolescent sample in this study reported having ridden in a car with a drinking driver in the past year. This prevalence falls within the range reported in other studies: a Canadian study reported that $54 \%$ of Grade 10 and 12 students had ever ridden with an adult who had been drinking alcohol (Leadbeater et al., 2008); another Canadian study reported that 23\% of 9 th to 12th graders had ridden in a car with a driver who had had too much to drink in the past year (Poulin et al., 2007); a U.S. study found $45 \%$ of $15-20$ year olds in California had ridden with a drinking driver in the past year (Chen et al., 2008); and a national U.S. study found $28 \%$ of 9 th to 12 th graders had rode in a vehicle driven by someone who had been drinking alcohol in the past 30 days (Centers for Disease Control and Prevention, 2010). The risk to these adolescent passengers in terms of immediate safety has been well established but the negative influence of observing others' drink driving on their future driving behaviours is identified here as a further risk.

This study confirms previous findings that being male and sensation seeking may also be risk factors for DUI. Other potential risk factors for DUI, such as binge alcohol use, friends' alcohol use and family factors, whilst showing bivariate relationships with DUI, became statistically non-significant in the multivariate model. These findings suggest that adolescent exposure to others' drink

Table 2

Logistic regression models predicting young adult DUI.

\begin{tabular}{|c|c|c|c|c|}
\hline & \multicolumn{2}{|c|}{ Bivariate models } & \multicolumn{2}{|c|}{ Multivariate model } \\
\hline & OR & $95 \% \mathrm{CI}$ & OR & $95 \% \mathrm{CI}$ \\
\hline Adolescent exposure to DUI & $2.13^{* * *}$ & $1.68-2.69$ & $1.62^{* *}$ & $1.23-2.13$ \\
\hline Gender - Male & $2.95^{* * *}$ & $2.31-3.76$ & $2.64^{* * *}$ & $2.02-3.43$ \\
\hline Age & $1.33^{* * *}$ & $1.24-1.44$ & $1.32^{* * *}$ & $1.16-1.50$ \\
\hline Binge drinking & $1.93^{* * *}$ & $1.52-2.46$ & 1.10 & $.79-1.53$ \\
\hline Sensation seeking & $1.42^{* * *}$ & $1.31-1.54$ & $1.24^{* * *}$ & $1.10-1.39$ \\
\hline Rebelliousness & $1.43^{* * *}$ & $1.20-1.69$ & .90 & $.72-1.13$ \\
\hline Family history of ASB & $1.42^{* * *}$ & $1.24-1.62$ & 1.11 & $.92-1.35$ \\
\hline Poor family management & $1.79^{* * *}$ & $1.45-2.22$ & 1.00 & $.75-1.33$ \\
\hline Family SES & $1.32^{*}$ & $1.04-1.66$ & $1.41^{* *}$ & $1.09-1.81$ \\
\hline Friends' drug use & $1.42^{* * *}$ & $1.27-1.59$ & .99 & $.83-1.17$ \\
\hline
\end{tabular}

Family history of ASB = family history of antisocial behaviour. Multivariate models control for all variables in table.

${ }^{*} p<.05$.

** $p<.01$.

${ }^{* * *} p<.001$. 
driving is highly associated with the social contextual factors of family history of antisocial behaviour, poor family management and peer drug use, as well as individual behaviours of binge drinking and rebelliousness. The finding that higher family SES is associated with increased DUI is in contrast to some previous reports (Morrison et al., 2002; Vaez and Laflamme, 2005). It is possible that the observed positive relationship with SES relates to increased access to alcohol and motor vehicles and less vigilance from police in the form of random breath testing (RBT) in high SES areas. The observed increased risk with age may be reflective of older participants having greater access to alcohol and motor vehicles, possibly from increased income. This finding may also reflect the nature of the measurement used, as older participants would have had a longer time period since gaining their license during which to DUI.

\subsection{Strengths and limitations}

As with all studies, the results of this study should be interpreted in light of its potential limitations. The self-report measure of DUI might have led to underestimations due to the potentially illegal nature of the behaviour. However, respondents were assured of the confidential nature of their responses and mostly completed the survey online which would have provided a greater sense of privacy and confidentiality. Also, it has been argued that self-report is the most appropriate method of measuring antisocial behaviours that may not be detected by others and therefore underestimated in objective evaluations (Jolliffe et al., 2003). The rate of self-reported DUI (18\%) in this study is consistent with previous reports based on Australian youth (Davey et al., 2005; Vassallo et al., 2010) and is considerably higher than rates ascertained using RBT (Wundersitz et al., 2009).

The wording of the outcome variable ("driven when probably affected by alcohol") rather than other measures such as the number of drinks consumed in a specified period before driving or BAC level was a deliberate attempt to measure self-perceived impaired driving rather than actual intoxication. This approach captures the development of attitudes towards 'safe' driving behaviour because participants indicated having driven despite feeling the effects of alcohol. However, it should be acknowledged that perceptions of intoxication are likely to vary between individuals. Further investigations using alternative measures of DUI would be beneficial. Nevertheless, perceptions of intoxication are important because even being slightly above the BAC limit greatly increases the risk of fatal accidents (Phillips and Brewer, 2011).

The exposure variable used in this study did not provide information on who the drinking driver was (parent, sibling, friend or other adult) or how much they had drunk. Further studies could investigate the differences in influences between different types of driver and whether this influence changes at different stages of adolescence. Measurement of the amount of alcohol consumed might help determination of the modelling and influence of views that "a little over the legal limit" is safe and acceptable driving behaviour. This is an important area of concern since casualty crash risk doubles when driving with a BAC just above the legal limit, and the risk of a fatal crash rises more sharply (Office of Road Safety, 2012).

Parent alcohol use is a known predictor or young adult DUI (Maldonado-Molina et al., 2011) but was not measured directly in this study. The measure of family history of antisocial behaviour, which incorporates sibling and adult drug and alcohol use as well as other types of antisocial behaviour, was used as an alternative measure. This broader measure was considered more relevant given the exposure variable used in this study did not define the relationship of the drinking driver to the respondent.

Some studies have identified a relationship between rural (nonmetropolitan) living status and DUI (Leadbeater et al., 2008). The current study did not collect location information in young adulthood and so could not account for any possible effects of rural living status on DUI. Location information was available for the school of each adolescent participant at the time of the first survey. A possible link was explored but no association was found between time 1 location as measured on the Australian Remoteness Index for Areas (ARIA) (Australian Bureau of Statistics, 2003) and young adult DUI.

The exposure variable was measured 6-7 years before the outcome variable and so it is possible that other factors over the intervening time could have modified the effect on the outcome variable. Furthermore, the current outcome variable required participants to report on any DUI behaviour 'since getting a license', rather than within the past year, as the exposure variable did. The findings of this study suggest that there is a link, particularly evidenced by the association remaining when the influence of a range of important risk factors was controlled for. Nevertheless, future research should consider the use of other statistical techniques such as "growth modelling" to help better understand the association between exposure to riding with a drinking driver and cumulative DUI across an extended period of time.

Despite these limitations, this study has extended the findings of previous investigations of the personal and socio-contextual influences on DUI behaviour. Whilst previous studies have been limited by their sample design or the range of potential risk factors for which they accounted, this study has utilised a large community sample to prospectively measure the influence of a range of potential factors in mid to late adolescence on later DUI. Retention rates across the 6-7 years of the study were high so negative effects due to sample attrition are minimal.

\subsection{Implications}

The finding that exposure in adolescence to others' drink driving increases the risk of self-reported DUI has important implications for prevention efforts. Most of the current measures aimed at preventing youth drink driving are based on structural, legal and policy changes. For example, higher minimum drinking ages (Wagenaar and Toomey, 2002), graduated licensing schemes (Russell et al., 2011; Shope, 2007) and increased policing and enforcement of drink driving laws have all been shown to be effective. Some have argued, however, that further gains could be made by targeting key aspects of the individual and social context within which DUI behaviours develop (Chen et al., 2008; Shults et al., 2009; Vassallo et al., 2007). The findings of this study suggest that adult role modelling of DUI to adolescents is one influence that could be focused upon.

Efforts to reduce adolescents riding with a drinking driver might target either the adult driver or the adolescent passenger. In the former case adult education via social media campaigns on the harmful effect of role modelling DUI behaviour would be warranted. One group that might be particularly susceptible to such messages is parents of younger aged children. It has been estimated that children in New South Wales, Australia are subject to 16 years of watching their parents drive before they embark on driver training themselves (Papakosmas and Noble, 2011). Awareness campaigns may also involve broader efforts to change community attitudes on the acceptability of drink driving and improve knowledge of the relationship between alcohol intake and impairment. Similar efforts have been made in relation to the harmful effect of child exposure to environmental tobacco smoke in cars. In this case legislation specifically targeting this behaviour has been successfully introduced and may be a method of conveying the seriousness of poor role modelling and exposing children to risk. The second form of prevention campaign involves downstream approaches that provide adolescents with tools and strategies for avoiding riding with a drinking driver. Many determinants are out of the 
control of younger adolescents but as they get older they are able to exert more influence over decisions. Harm reduction programs could educate on safe alcohol consumption rates for driving and refusal skills to help adolescents say no to alcohol impaired adults (which during later adolescence age may include parents, peers or siblings) offering to drive them. A number of school-based programs have been implemented with some evidence of effectiveness for reducing riding with drinking drivers (Elder et al., 2005).

\section{Conclusion}

Rather than aiming to develop a broad based predictive model, the purpose of the current study was to specifically examine the relationship between riding with a drinking driver in the teens and subsequent DUI in young adulthood, net of a comprehensive range of potential confounding factors. The findings have important implications for adult drivers in the community who are acting as role models for adolescents riding in vehicles with them. The implications of DUI extend beyond the immediate risk to the driver of police enforcement, accident and injury to influence on young people exposed to their risky behaviour and the behaviour of future drivers. Incorporation of this message into safe drink drive media campaigns targeting parents and other adults may be an effective addition to existing enforcement policies which strive to reduce the unacceptable death and injury rate related to DUI.

\section{Acknowledgements}

We would like to express our gratitude to the participants of the International Youth Development Study. Further information is available from the IYDS website (http://www.iyds.org). The authors are grateful for the financial support of the National Institute on Drug Abuse (R01-DA012140) for the International Youth Development Study initial data collection and the National Institute on Alcoholism and Alcohol Abuse (R01AA017188-01) for analysis of the data. Continued data collection in Victoria, Australia has been supported by three Australian Research Council Discovery Projects (DPO663371, DPO877359, and DP1095744) and an Australian National Health and Medical Research Council grant (NHMRC; project number 594793). The IYDS was also supported by the Victorian Government's Operational Infrastructure Support program. The content is solely the responsibility of the authors and does not necessarily represent the official views of the sponsors.

\section{References}

Akers, R.L., 1985. Deviant Behavior: A Social Learning Approach. Wadsworth, Belmont, CA.

Arthur, M.W., Hawkins, J.D., Pollard, J.A., Catalano, R.F., Baglioni, A.J., 2002. Measuring risk and protective factors for substance use, delinquency, and other adolescent problem behaviors. The communities that care youth survey. Evaluation Review 26, 575-601.

Australian Bureau of Statistics, 2003. ASGC Remoteness Classification: Purpose and Use (Census Paper No. 03/01), Canberra.

Australian Bureau of Statistics, 2008. Australian social trends. ABS catalogue no. 4102.0. Australian Bureau of Statistics. Available at: http://www.abs.gov.au/AUSSTATS/abs@.nsf/Lookup/4102.0Main+Features6200 8? OpenDocument

Australian Institute of Health and Welfare, 2008. Injury Among Young Australians. AIHW Bulletin Series No. 60. Cat. No. AUS 102. AIHW, Canberra.

Australian Medical Association, 2009. Alcohol use and harms in Australia. Australian Medical Association. Available at: http://ama.com.au/node/4762

Australian Transport Council, 2008. National road safety action plan 2009 and 2010. Australian Government Publishing Service, Canberra.

Bandura, A., 1977. Social Learning Theory. Prentice-Hall, Englewood Cliffs, NJ.

Bandura, A., 1986. Social Foundations of Thought and Action: A Social Cognitive Theory. Prentice-Hall, Englewood Cliffs, NJ.

Beck, K.H., Kasperski, S.J., Caldeira, K.M., Vincent, K.B., O’Grady, K.E., Arria, A.M., 2010. Trends in alcohol-related traffic risk behaviors among college students. Alcoholism: Clinical and Experimental Research 34 (8), 1472-1478.

Bina, M., Graziano, F., Bonino, S., 2006. Risky driving and lifestyle in adolescence. Accident Analysis and Prevention 38, 472-481.
Bingham, C.R., Elliott, M.R., Shope, J.T., 2007. Social and behavioral characteristics of young adult drink/drivers adjusted for level of alcohol use. Alcoholism: Clinical and Experimental Research 31 (4), 655-664.

Brener, N.D., Kann, L., McManus, T., Kinchen, S.A., Sundberg, E.C., Ross, J.G., 2002 Reliability of the 1999 Youth Risk Behavior Survey questionnaire. Journal of Adolescent Health 31, 336-342.

Catalano, R.F., Hawkins, J.D., 1996. The Social Development Model: A The ory of Antisocial Behaviour. In: Hawkins, J.D. (Ed.), Delinquency and Crime: Current Theories. Cambridge University Press, New York, pp 149-197.

Cavallo, A., Triggs, T.J., 1996. Directions for improving young driver safety within Victoria: a discussion paper. Monash University Accident Research Centre, Melbourne, Vic.

Center for Behavioral Health Statistics and Quality, 2011. Adolescents Living With a Parent Who Drives Under the Influence Are at Increased Risk for Driving Under the Influence Themselves. Substance Abuse and Mental Health Services Administration (SAMHSA), Data Spotlight: December 6, 2011, Available at: http://www.samhsa.gov/data/spotlight/WEB_SPOT_023/WEB_SPOT_023.pdf

Centers for Disease Control and Prevention, 2010. Youth risk behavior surveillance - United States, 2009 surveillance summaries [June]. MMWR 59 (no. SS-5).

Chen, M.J., Grube, J., Nygaard, W., Miller, P.B.A., 2008. Identifying social mechanisms for the prevention of adolescent drinking and driving. Accident Analysis and Prevention 40, 576-585.

Davey, J.D., Davey, T., Obst, P.L., 2005. Drug and drink driving by university students: an exploration of the influence of attitudes. Traffic Injury Prevention 6 (1) 44-52.

Elder, R.W., Nichols, J.L., Shults, R.A., Sleet, D.A., Barrios, L.C., Compton, R., 2005 Effectiveness of school-based programs for reducing drinking and driving and riding with drinking drivers. A systematic review. American Journal of Preventive Medicine 28 (Suppl.), 288-304

Engström, I., Gregersen, N.P., Hernetkoski, K., Keskinen, E., Nyberg, A., 2003. Young Novice Drivers, Driver Education and Training: Literature Review. Swedish National Road and Transport Research Institute, Linköping, Sweden.

Evans-Whipp, T.J., Bond, L., Toumbourou, J.W., Catalano, R.F., 2007. School, parent, and student perspectives of school drug policies. Journal of School Health 77 (3), $138-146$.

Ferguson, S.A., Williams, A.F., Chapline, J.F., Reinfurt, D.W., De Leonardis, D.M., 2001 Relationship of parent driving records to the driving records of their children. Accident Analysis and Prevention 33, 229-234.

Fernandes, R., Job, R.F.S., Hatfield, J., 2007. A challenge to the assumed generalizability of prediction and countermeasure for risky driving: different factors predict different risky driving behaviors. Journal of Safety Research 38 (1), 59-70.

Finken, L.L., Jacobs, J.E., Laguna, K.D., 1998. Risky drinking and driving/riding decisions: the role of previous experience. Journal of Youth Adolescence 27 (4) 493-511.

Glaser, R.R., Van Horn, M.L., Arthur, M.W., Hawkins, J.D., Catalano, R.F., 2005 Measurement properties of the Communities That Care youth survey across demographic groups. Journal of Quantitative Criminology 21, 73-102.

Gulliver, P., Begg, D., 2004. Influences during adolescence on perceptions and behaviour related to alcohol use and unsafe driving as young adults. Accident Analysis and Prevention 36, 773-781.

Hawkins, J.D., Smith, B.L., Hill, K.G., Kosterman, R., Catalano, R.F., Abbott, R.D., 2003 Understanding and preventing crime and violence: findings from the Seattle social development project. In: Thornberry, T.P., Krohn, M.D. (Eds.), Taking Stock of Delinquency: An Overview of Findings from Contemporary Longitudinal Studies. Kluwer Academic/Plenum Publishers, New York, pp. 255-312.

Hingson, R.W., Zha, W., Weitzman, E.R., 2009. Magnitude of and trends in alcoholrelated mortality and morbidity among U.S. College students ages 18-24 1998-2005. Journal of Studies on Alcohol and Drugs (Suppl. 16), 12-20.

Hoyert, D.L., Kung, H.C., Smith, B.L., 2005. Deaths: preliminary data for 2003. National Vital Statistics Reports, vol. 53, no. 15. National Center for Health Statistics, Hyattsville, MD.

Jolliffe, D., Farrington, D.P., Hawkins, J.D., Catalano, R.F., Hill, K.G., Kosterman, R. 2003. Predictive, concurrent, prospective and retrospective validity of selfreported delinquency. Criminal Behavior and Mental Health 13 (3), 179-197.

Jonah, B.A., Thiessen, R., Au-Yeung, E., 2001. Sensation seeking, risky driving and behavioral adaptation. Accident Analysis and Prevention 33 (5), 679-684.

LaBrie, J.W., Kenney, S.R., Mirza, T., Lac, A., 2011. Identifying factors that increase the likelihood of driving after drinking among college students. Accident Analysis and Prevention 43, 1371-1377.

LaBrie, J.W., Migliuri, S., Kenney, S.R., Lac, A., 2010. Family history of alcohol abuse associated with problematic drinking among college students. Addictive Behaviors 35, 721-725.

Leadbeater, B.J., Foran, K., Grove-White, A., 2008. How much can you drink before driving? The influence of riding with impaired adults and peers on the driving behaviors of urban and rural youth. Addiction 103 (4), 629-637.

Maldonado-Molina, M.M., Reingle, J.M., Delcher, C., Branchini, J., 2011. The role of parental alcohol consumption on driving under the influence of alcohol: results from a longitudinal, nationally representative sample. Accident Analysis and Prevention 43 (6), 2182-2187.

McCarthy, D.M., Pedersen, S.L., 2009. Reciprocal associations between drinking-anddriving behavior and cognitions in adolescents. Journal of Studies on Alcohol and Drugs 70 (4), 536-542.

McMorris, B.J., Hemphill, S.A., Toumbourou, J.W., Catalano, R.F., Patton, G.C., 2007 Prevalence of substance use and delinquent behavior in adolescents from Victoria, Australia and Washington State, United States. Health Education and Behavior 34 (4), 634-650. 
Morrison, L., Begg, D.J., Langley, J.D., 2002. Personal and situational influences on drink driving and sober driving among a cohort of young adults. Injury Prevention 8 (2), 111-115.

National Highway Traffic Safety Administration, 2004. Traffic Safety Facts 2003 Annual Report: Early Edition. U.S. Department of Transportation, Washington, DC.

Office of Road Safety, 2012. Drink driving fact sheet. Government of Western Australia. Available at: http://www.ors.wa.gov.au/Documents/DrinkDriving /drinkdriving-factsheet-may2012.aspx

Palamara, P.G., Legge, M., Stevenson, M.R., 2001. An investigation of the relationship between years of licensing, traffic offences, and crash involvement: a comparison of first year drivers with drivers licensed for ten years and five years. Injury Research Centre, University of Western Australia, Crawley, Australia.

Papakosmas, M.F., Noble, G., 2011. Parents and young drivers: the role of learning, behaviour modelling, communication and social marketing. Journal of the Australasian College of Road Safety 22 (1), 45-52.

Pedersen, S.L., McCarthy, D.M., 2008. Person-environment transactions in youth drinking and driving. Psychology of Addictive Behaviors 22 (3), 340-348.

Phillips, D.P., Brewer, K.M., 2011. The relationship between serious injury and blood alcohol concentration (BAC) in fatal motor vehicle accidents: $\mathrm{BAC}=0.01 \%$ is associated with significantly more dangerous accidents than $\mathrm{BAC}=0.00 \%$. Addiction 106 (9), 1614-1622.

Poulin, C., Boudreau, B., Asbridge, M., 2007. Adolescent passengers of drunk drivers: a multi-level exploration into the inequities of risk and safety. Addiction 102 (1), 51-61.

Prior, M., Sanson, A., Smart, D., Oberklaid, F., 2000. Pathways from infancy to adolescence: Australian Temperament Project 1983-2000. Australian Institute for Family Studies, Melbourne, Australia, ISBN: 0642394784.

Reeder, A.I., Alsop, J.C., Begg, D.J., Nada-Raja, S., McLaren, R.L., 1998. A longitudinal investigation of psychological and social predictors of traffic convictions among young New Zealand drivers. Transportation Research Part F: Traffic Psychology and Behaviour 1 (1), 25-46.

Russell, K., Vandermeer, B., Hartling, L., 2011. Graduated driver licensing for reducing motor vehicle crashes among young drivers. Cochrane Database Systematic Review 10, CD003300.

Shope, J.T., 2007. Graduated driver licensing: review of evaluation results since 2002. Journal of Safety Research 38, 165-175.

Shults, R.A., Elder, R.W., Nichols, J.L., Sleet, D.A., Compton, R., Chattopadhyay, S.K., 2009. Guide to community preventive services: effectiveness of multicomponent programs with community mobilization for reducing alcoholimpaired driving. American Journal of Preventive Medicine 37, 360-371.

Siskind, V., Steinhardt, D., Sheehan, M., O'Connor, T., Hanks, H., 2011. Risk factors for fatal crashes in rural Australia. Accident Analysis and Prevention 43, 1082-1088.
Tin Tin, S., Ameratunga, S., Robinson, E., Crengle, S., Schaaf, D., Watson, P., 2008. Drink driving and the patterns and context of drinking among New Zealand adolescents. Acta Paediatrica 97 (10), 1433-1437.

Tomas Dols, S., González, F.J.Á., Aleixandre, N.L., Vidal-Infer, A., Rodrigo, M.J.T., Valderrama-Zurián, J.C., 2010. Predictors of driving after alcohol and drug use among adolescents in Valencia (Spain). Accident Analysis and Prevention 42 (6), 2024-2029.

Transport Accident Commission of Victoria, 2003. Young driver statistics (2002). Available at: http://www.tacsafety.com.au/jsp/content/NavigationController. do? areaID=13\&tierID=1\&navID=AF3476DD\&navLink=null\&pageID=209

Vaez, M., Laflamme, L., 2005. Impaired driving and motor vehicle crashes among Swedish youth. An investigation into drivers' sociodemographic characteristics. Accident Analysis and Prevention 37, 605-611.

Vassallo, S., Smart, D., Cockfield, S., Gunatillake, T., Harris, A., Harrison, W., 2010. In the driver's seat ii: Beyond the early driving years. Research Report No. 17. Australian Institute of Family Studies, Melbourne.

Vassallo, S., Smart, D., Sanson, A., Dussuyer, I., McKendry, B., Toumbourou, J.W., 2002. Patterns and Precursors of Adolescent Antisocial Behaviour: The First Report December 2002. Crime Prevention Victoria. Melbourne.

Vassallo, S., Smart, D., Sanson, A., Harrison, W., Harris, A., Cockfield, S., McIntyre, A., 2007. Risky driving among young Australian drivers: trends, precursors and correlates. Accident Analysis and Prevention 39 (3), 444-458.

Wagenaar, A.C., Toomey, T.L., 2002. Effects of minimum drinking age laws: Review and analyses of the literature from 1960-2000. Journal of Studies on Alcohol and Drugs (Suppl. (14)), 2006-2225.

Ward, B., Snow, P., James, E., Griffith, J., 2010. The Influence of Parents and Siblings on Children's and Adolescents' Alcohol Use: A critical review of the literature. Drinkwise Australia. Available at: http://www.drinkwise.org.au/free-resources/research/the-influence-of-parents -and-siblings-on-childrens-and-adolescents-attitudes-and-behaviours-towards -alcohol-a-critical-review-of-the-literature/

Winters, K.C., Henly, G.A., 1989. Personal Experiences Inventory Test \& Test Manual. Western Psychological Services, Los Angeles, CA.

Wundersitz, L.N., Hiranandani, K., Baldock, M.R.J., 2009. Annual Performance Indicators of Enforced Driver Behaviours in South Australia, 2007. Centre for Automative Safety Research, University of Adelaide. Available at: http://casr.adelaide.edu.au/publications/researchreports/casr058.pdf

Zakletskaia, L.I., Mundt, M.P., Balousek, S.L., Wilson, E.L., Fleming, M.F., 2009. Alcoholimpaired driving behavior and sensation-seeking disposition in a college population receiving routine care at campus health service centers. Accident Analysis and Prevention 41, 380-386. 